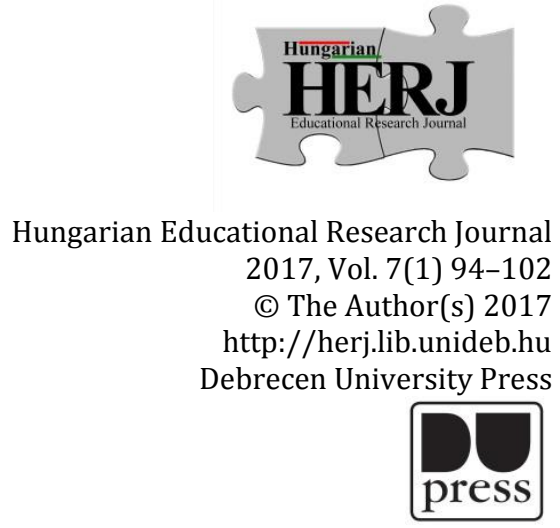

DOI: 10.14413/herj.2017.01.07.

\author{
Hungarian Educational Research Journal \\ 2017, Vol. 7(1) 94-102 \\ The Author(s) 2017 \\ http://herj.lib.unideb.hu
}

\section{New chapter of knowledge management in Hungary: steps toward open science and tertiary collaborative work}

\author{
Gyongyi Karacsony ${ }^{1}$ \& Edit Gorogh ${ }^{2}$
}

\begin{abstract}
The beginning of the 21st century has brought a paradigm change in higher education. The technological improvements in research and knowledge discovery and the strengthening discourse of open access have introduced new methods and tools of teaching and learning. The free online availability of teaching materials and the easy access to research results and data facilitate the development of research and student collaborative networks on a global level. Through the cooperation and works of such scientific networks, the core principles of open science - transparency, reusability, and collaboration - can be realised. A gradual shift towards the open scientific discourse can be detected in Hungary, as well. A growing number of higher education institutions adopt open access guidelines in their research and publication policies. The strengthening national open science advocacy and the EU funding requirements, requesting more transparent and freely accessible research processes, encourage a more standardized national vision on research and teaching methodologies. Collaborations with research communities and higher education administrations could ensure a more solid position for us in the global scientific circulation.
\end{abstract}

Keywords: open access, open science, scholarly networks

\footnotetext{
1 University of Debrecen (Hungary), Email address: gyk@lib.unideb.hu

2 University of Debrecen (Hungary), Email address: editg@lib.unideb.hu

Recommended citation format: Karacsony, Gy. \& Gorogh, E. (2017). New chapter of knowledge management in Hungary: steps toward open science and tertiary collaborative work. Hungarian Educational Research Journal, 7(1), 94-102, DOI: 10.14413/herj.2017.01.07.
} 


\section{Introduction}

The beginning of the 21st century has brought a paradigm change in higher education. The technological improvements in research and knowledge discovery and the strengthening discourse of open access have introduced new methods and tools of teaching and learning. The free online availability of teaching materials and the easy access to research results and data facilitate the development of research and student collaborative networks on a global level. Through the cooperation and works of such scientific networks, the core principles of open science - transparency, reusability, and collaboration - can be realised. A gradual shift towards the open scientific discourse can be detected in Hungary, as well. A growing number of higher education institutions adopt open access guidelines in their research and publication policies. The strengthening national open science advocacy and the EU funding requirements, requesting more transparent and freely accessible research processes, encourage a more standardized national vision on research and teaching methodologies. Collaborations with research communities and higher education administrations could ensure a more solid position for us in the global scientific circulation.

\section{Background}

\section{Transforming tertiary education}

The present performance of research and teaching communities is greatly affected by two major factors on a global level. The driving forces behind the transforming tertiary educational landscape are the changing knowledge acquisition methods and processes, and as an overarching discourse of research and education, the strengthening presence of open access.

An extensive study funded by the European Commission examines the impact of open science on tertiary education systems from the perspective of new forms of knowledge acquisition and production. The report provides an overview of the primary reasons knowledge discovery has fundamentally changed in the past decades. Knowledge is power: it has indeed become the most important factor in economic development, it contributes to economic analysis and related decision-making processes. The global primacy of information and knowledge has been marked by the increasing use of the internet. The wide spread of computing technology and skills and the decreasing costs of communication have contributed to really fast information exchange and data storage. The products of the communication revolution have altered the learning processes at higher education institutions, as well. Technological innovations have made way to interactive and peer-based learning, mass online open courses link students all over the world. Furthermore, new assessment measurements such as the global rankings allow to measure and compare the performance of universities across all continents, and student engagement surveys measure the degree of student satisfaction with the quality of 
teaching and learning. (Salmi) All these innovative tools and teaching methods bring institutions closer together forming a global classroom.

\section{Open science}

The other major factor which has to be taken into account in the transforming higher education environment is open access. Although the discourse on open access has been evolving only for a couple decades now, it has grown into a major driving force in research. The European Commission is moving beyond open access towards the more inclusive area of open science. Elements of open science will gradually feed into the shaping of national and EU policies for research and innovation and eventually contribute to the realisation of the European Research Area and the Innovation Union, the two main flagship initiatives of the EU (Donelly 2015).

Open science is defined broadly as "a systemic change in the modus operandi of doing research and organizing science" (EC). Although the unified definition of open science has not been pinpointed, the major goals of open research can be inevitably identified. These imperatives include the

- transparency in experimental methodology, observation, and collection of data,

- public availability and reusability of scientific data,

- public accessibility and transparency of scientific communication,

- using web-based tools to facilitate scientific collaboration (Gezelter 2009).

In his vision of open science, Peter Kraker (et al.) sees four basic instruments at play:

1. open access as a way to make research results available,

2. open data as a way to publish the raw data,

3. open source as a way to give access to research prototypes,

4. open methodology standing for sharing the methodological details of the study provided, and the tools used for data collection and analysis.

OpenScienceASAP has stepped further and added two more aspects of Kraker`s research processes which contribute to open science: open peer review introducing new assessment methods and tools, and open educational resources reaching for free and open educational materials in higher education.

The Open Science movement is challenging conventional approaches in order to promote research and development activities in an effective manner. It offers a new look at scientific development, using networks of research communities and advanced technologies to enhance collaborative work. Rather than restricting the "ownership" of discoveries and knowledge acquisition Open Science encourages research and education based on openness and sharing. 
Universities are gradually recognizing the need for shifting and transforming established structures and practices in research, teaching, and operations in order to meet current EU funding and policy recommendations.

\section{Open research and open data}

In light of knowledge exchange and innovation, the EC mandates providing open access to research results in all scientific fields. This strategy supports the requirements of the present funding program, Horizon2020. From 2014 all projects, funded within the H2020 framework, are required to provide open access to their research outputs either publishing in an open access journal (Gold OA) or providing access to an institutional repository (Green OA). In the European scholarly communication special attention is drawn to enhanced publication which is a research publication supplemented by further documentation, such as research data, information about the author, etc.

The current EU research program supports the open exchange, accessibility, and reusability of research data. In the frame of H2020, the EU has launched the Research Data Pilot which is an initiative to provide open access to research data from publicly funded projects with regard to sensitive or protected data. The primary goals of the pilot are to develop secure data exchange work processes, to ensure the quality of data and to prepare data management policies on institutional and national levels, as well. Although from the beginning of 2017 all research fields are obliged to comply with $\mathrm{H} 2020$ requirements, the option is given to all projects to opt out if their data collection procedures and the nature of the data do not allow data sharing.

Thus, the words of former Vice-President of the European Commission responsible for the Digital Agenda, Neele Kroes has been validated by the current actions and recommendations of the EC:

"In the digital age, data takes on a whole new value, and with new technology we can do great things with it. Opening it up is not just good for transparency; it also stimulates great web content, and provides the fuel for a future economy. That's why I say that data is the new oil for the digital age."

\section{Open educational resources}

The term was firstly coined at UNESCO's 2002 Forum on Open Courseware and designates "teaching, learning and research materials in any medium, digital or otherwise, that reside in the public domain or have been released under an open license that permits no-cost access, use, adaptation and redistribution by others with no or limited restrictions". Often cited is the William and Flora Hewlett Foundation term which defines OER as: "teaching, learning, and research resources that reside in the public domain or have been released under an intellectual property license that permits their free use and re-purposing by others. Open educational resources include full courses, course materials, modules, textbooks, streaming videos, tests, software, and any other tools, materials, or techniques used to support access to knowledge". 
The strengthening presence of open educational resources is ignited by globalisation, the competition between higher educational institutions and the rapid technological developments. These movements are accompanied by the increasing presence of the open access discourse in academia which contributes to the sharing and collective development of learning resources.

Using open source materials and open resources has several benefits for tertiary institutions:

- the main principle of academic institutions is to share knowledge,

- publicly funded higher education institutions should allow share and reuse of resources by the public,

- sharing and reusing can contribute to quality improvement and reduction of costs,

- open access resources can be used as a showcase for potential students,

- sharing will speed up the development of new learning resources, stimulate internal improvement and innovation (OECD 2007).

According to OECD in 2007, there are materials from more than 3000 open access courses (open courseware) currently available from over 300 universities worldwide.

\section{Collaboration in research and teaching: rise of networks}

As open science is gaining momentum in global scholarly communication, a realignment of priorities, relations, and processes can be observed. Through the rapid development of interactive and collaborative modes of knowledge acquisition, generation and dissemination, which are facilitated by modern information and communication tools, collaborations and the rise of research networks have come to characterize research on a global level. These network- based programs and projects entail numerous benefits not just for the individual researchers involved, but also for the affiliated institutions.

There are an increasing number of international projects working with researchers not only from different countries but also from different disciplines producing multi-authored papers and reports. These collaborative works receive more visibility since due to their multidisciplinary inputs, they carry relevance to multiple fields, and have a higher impact since they get cited more often.

Research networks have the opportunity to work with a variety of resources. Researchers contribute to these collaborative works with the facilities they have access to and with the funding their institutions provide. Furthermore, in the current EU funding scheme collaborative projects and consortium-based applications are more preferred since they encourage a rapid and wide spread of knowledge.

According to Adams (2012), research networks are also a tool of international diplomacy. Germany exports excellent research equipment within its partnerships. China expands its cultural influence through the regional programmes it funds. Thus, they definitely play a 
role not only in the scholarly environment, but they expand their effect to the social and economic realms of life.

In the Study on Open Science, Salmi points out the role collaborative work has in the transforming tertiary education systems. The rise of multidisciplinarity and the emergence of collaborative modes of knowledge transmission and generation reshape higher education. Traditional disciplines and methods, which are characterized by overspecialization and segmentation, are increasingly challenged by developments in new scientific and technological fields. Therefore, a shift toward a problem-based mode of production of knowledge can be detected, which results in the blurring of the distinction between basic and applied research (e.g., biology and biotechnology, nanotechnology, genomics and proteomics, advanced materials science, microelectronics, information systems, robotics, intelligent systems and neuroscience, and environmental science and technology). Considering the increasingly multidisciplinary nature of these research fields, education in these fields requires the integration of a number of disciplines that were previously regarded as separate and distinct. The result is the multiplication of interdisciplinary and multidisciplinary programs that cut across traditional disciplinary barriers.

\section{Open access in Hungary}

The Hungarian open access landscape shows a rather diverse picture. In lack of a unified national open access vision, research and tertiary institutions initiate their own open access programs without collaborations or efforts to cooperate. Based on the participations in international projects in which open access issues are quite often included in the research flow, and on the available resources, some institutions are more willing to incorporate open access guidelines in their operational and development strategies than others. Therefore, a huge gap can be detected both in awareness and in implementations of open access related innovations between regions and institutions.

\section{Hungarian Academy of Science}

One of the active players in the Hungarian open access field is the Hungarian Academy of Science (MTA). The institution has an OA mandate effective from January 1, 2013 requiring researchers and employees of the MTA to make their scientific publications open access either through self-archiving in institutional or discipline-based repositories or by publishing them in OA journals or in hybrid journals offering paid open access. MTA operates several open access repositories for various collections (REALd/EOD/MS/Ph.D./J/R) in order to support researchers to comply with funding and governmental requirements, such as the Law of Higher Education of 2013 on providing open access to Ph.D. dissertations. Furthermore, a centralised publication database Magyar Tudomanyos Muvek Tara (MTMT)- is developed aiming at collecting publication metadata from all Hungarian research and higher education institutions. The repositories 
connected to MTMT provide the opportunity for those researchers whose institution does not operate an institutional repository to upload their research outputs.

\section{University repositories}

Several higher education institutions operate their own institutional repository. They are joined together in an association of Hungarian Open Access Repositories (HUNOR), coordinated by the University Debrecen University and National Library. Through this network, information is disseminated about the current international and national developments in research management and scholarly communication. Institutions are informed about the international standards of repository and data management and they are urged to comply all new developments and already operating data archives with these standards.

In the open access discourse, institutional repositories play a significant role: they foster the Green OA strategy. The self-archiving process can further be facilitated by institutional open access mandates which usually require the researchers of the institutions to deposit their research outputs to the repository and provide access to them as copyright and publisher provisions allow. A Pasteur40A briefing paper on open access mandate support, prepared recently by the Hungarian Academy of Sciences, reviews the basic supporting actions that are necessary for a successful OA mandate with a high compliance rate (Holl 2014). One of the key supporting mechanisms involves the integration of repositories into the research flow and their connection to internal and external systems, such as research information systems (CRIS). The reluctance of researchers derives from the multiple logins to the various systems and separate deposits they require. The interconnectedness and interoperability of these systems, allowing for easy transfer of data once deposited, would definitely decrease the researchers` administrative burden and would promote a more willing compliance with depositing requirements.

The Hungarian repository landscape is definitely showing a move along open access guidelines. There is a growing number of higher education institutions which consider a repository important in their research management, and which direct repository developments in accordance with the international open access standards. The main directions for these improvements and developments are basically given by the requirements of the EU funding scheme and open access recommendations of EC guidelines. Furthermore, EU-funded programs, such as OpenAIRE with the research data pilot and the Gold OA initiative, or Dart-Europe disclose concrete specifications an institutional repository has to comply with in order to participate in them. As pioneers in the Hungarian open access discourse, the University of Debrecen and the University of Szeged were among the firsts to incorporate open access goals and recommendation in their institutional publication policies. But there are several other repository developments are ongoing in higher education (11 institutional repositories operated by 8 universities). 
Open access guidelines are present in the Hungarian scholarly discourse, and they direct technological and administrative decision-making processes. Related initiatives are recorded in various databases showcasing a growing interest in open access issues:

- 28 publishers with 120 journals are registered in the Sherpa/Romeo database with references to their open access policies,

- 27 open access journals are registered in DOAJ,

- 32 repositories are recorded in the OPENDOAR database,

- 3 mandates are included in the ROARMAP registry.

There are also good examples of innovative initiatives in Hungarian scholarly communication. The NextGeneration project of the Institute for Computer Science and Control of the Hungarian Academy of Sciences has developed a platform for active publications. The primary aim of the initiative is to change the passive article reading process into an active, discovery and social activity. This new type of publication is enhanced by scientific research data, annotations and metadata. This way it supports the browsing of related research results and data leading to an interrelated network of scientific outputs (Turbucz et al. 2014).

Such programs could find a wider application and testing ground if repository developments were aligned with each other. Through a network-based approach and collaborations among existing repositories and data archives in planning, technological improvements could be harmonized to avoid parallel developments and to consider budget issues.

\section{Conclusion}

Open access is slowly but surely seeping into the scientific discourse in Hungary. It shapes communication among institutions, administration, and other stakeholders. Due to the international research activities of our scientists and teachers, and participation of universities in global programs, EU publishing and data management guidelines are influencing decision making processes on technological, research and teaching developments. However, openness does not merely and necessarily imply immediate and free access to all results. It means:

- transparent research processes (for partners involved),

- opening up communication among stakeholders,

- harmonizing developments in terms of interoperability,

- sharing experiences.

The new chapter in knowledge management, both in research and teaching, should be defined by collaborative work among higher education and research institutions. Adapting the main principles of open access will just help this process on the way. 
This project has received funding from the European Union's Seventh Framework Programme for research, technological development and demonstration under grant agreement no 283595.

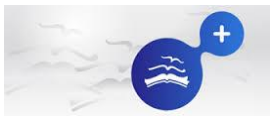

\section{References}

Adams, J. (2012). Collaborations: The rise of research networks. Oct. 2012. Nature 490: 335-336. doi:10.1038/490335a

Donelly, M. (2015). An overview of open science and open data in H2020. FOSTER. Retrieved from https://www.fosteropenscience.eu/content/overview-open-science-and-open-data-horizon-20200

EC Public Consultation 'Science 2.0': Science in Transition. Retrieved from https://ec.europa.eu/research/consultations/science-2.0/background.pdf

Gezelter, D. (2009). What, exactly, is Open Science? http://www.openscience.org/blog/?p=269

Holl, A., Bilicsi, E. \& Ball, D. (2016). PASTEUR4OA Briefing Paper: Open Access mandate support. Retrieved from http://www.pasteur4oa.eu/sites/pasteur4oa/files/resource/BP_Open\%20Access\%20Mandate\%2 OSupport.pdf

Holl, A. (2014). PASTEUR4OA - projekt az Europai Unio Open Access politikainak osszehangolasara. Tudomanyos es muszaki kozlemenyek. 61(9), 352-353.

Holl, A. (2014). Hungary Open Access Case Study. Pasteur4OA project report. Retrieved from http://www.pasteur4oa.eu/sites/pasteur4oa/files/resource/Hungary\%20Case\%20Study.pdf

Kraker, P. et. al. (2011) The case for an open science in technology enhanced learning. Int. J. Technology Enhanced Learning. 2011. 3 (6). 643-54

OECD. Giving Knowledge for Free: the Emergence of Open Educational Resources. 2007. Retrieved from https://www.oecd.org/edu/ceri/38654317.pdf

Open Educational Resources. The William and Flora Hewlett Foundation. Retrieved 20 June 2016. Retrieved from http://www.hewlett.org/programs/education/open-educational-resources

OpenScienceASAP. Was ist open science? Retrieved from http://openscienceasap.org/open-science/

Salmi, J. (2015). Impact, Implications and Policy Options. 2015. Retrieved from https://ec.europa.eu/research/innovation-union/pdf/expert-groups/rise/study_on_open_scienceimpact_implications_and_policy_options-salmi_072015.pdf

Turbucz, S., Micsik, A. \& Kovacs, L. (2014). Webes annotacios platform tudomanyos diskurzusokhoz. Networkshop 2014, 23-25 April 2014, Pecs, Hungary. 